\title{
BMJ Open Taking patients to the ice cream shop but telling them that they cannot have ice cream: a qualitative study of orthopaedic spine clinicians' perceptions of persistent low back pain consultations
}

Kathrin Louise Braeuninger-Weimer (1) , ${ }^{1}$ Naffis Anjarwalla, ${ }^{2}$ Alison H McGregor, ${ }^{3}$ Lisa Roberts (D) , ${ }^{4}$ Philip Sell, ${ }^{5}$ Tamar Pincus ${ }^{6}$

To cite: BraeuningerWeimer KL, Anjarwalla N, McGregor AH, et al. Taking patients to the ice cream shop but telling them that they cannot have ice cream: a qualitative study of orthopaedic spine clinicians' perceptions of persistent low back pain consultations. BMJ Open 2021;11:e052938. doi:10.1136/ bmjopen-2021-052938

- Prepublication history for this paper is available online. To view these files, please visit the journal online (http://dx.doi. org/10.1136/bmjopen-2021052938).

Received 02 May 2021 Accepted 02 September 2021

Check for updates

(c) Author(s) (or their employer(s)) 2021. Re-use permitted under CC BY-NC. No commercial re-use. See rights and permissions. Published by BMJ.

For numbered affiliations see end of article.

Correspondence to Professor Tamar Pincus; t.pincus@rhul.ac.uk

\section{ABSTRACT}

Objective This study aimed to explore the perceptions of orthopaedic clinicians about consultations for people with persistent musculoskeletal low back pain (PMLBP) in which surgery is not recommended. Surgery is not recommended for the majority of PMLBP consulting in secondary care settings.

Setting Secondary care sector in the UK.

Participants Semi-structured qualitative interviews were conducted with 24 orthopaedic team clinicians from 17 different hospitals in the UK and Ireland. Interviews explored clinicians' perceptions of the challenges in consultations where surgery is not indicated. Interviews were transcribed verbatim and analysed using thematic analysis.

Results Two meta-themes, Difficulties and Enablers, each consisting of several subthemes were identified. Difficulties included challenges around the choice of appropriate terminology and labels for PMLBP, managing patients' expectations, working with mentally vulnerable patients and explaining imaging findings. Enablers included early management of expectations, use of routine imaging, triaging, access to direct referral elsewhere, including other non-surgical practitioners in the team, training to improve communication skills and understanding of psychological issues.

Conclusion The findings highlight clinicians' perceived need for concordance in messages delivered across the care pathway and training of orthopaedic clinicians to deliver effective reassurance and address patients' needs in circumstances where surgery is not indicated.

\section{INTRODUCTION}

Surgical orthopaedic services in secondary care see many patients with persistent debilitating musculoskeletal low back pain (PMLBP) for whom surgery is not recommended. Such consultations can be challenging, because they often result in discharging patients without a clear diagnosis or a meaningful

\section{Strengths and limitations of this study}

- In-depth qualitative interviews with 24 orthopaedic spine clinicians from 17 different hospitals in the UK, ensuring geographical representation.

- The coding was carried out by several researchers, from different disciplines.

- There was a lack of female participants, which may bias the perspectives represented by clinicians.

- The study focused on UK-based clinicians, and is unlikely to represent other health settings.

management plan. There is little evidence to support the benefits of surgery in patients with PMLBP. ${ }^{1-3}$ The volume of spinal surgery in the UK remains high, with an annual cost of around £200million, and around 10000 patients going through spinal elective surgery every year. ${ }^{4}$ A recent longitudinal study in six UK hospitals found that around one in five patients consulting for back pain would be offered surgery. ${ }^{5}$ Although imaging should only be indicated for patients with 'red flags, ${ }^{6-8}$ in the UK it is common practice for the majority of patients consulting orthopaedic spine clinicians to receive an MRI scan. ${ }^{5}$ For people with PMLBP, imaging often reveals signs of degeneration ${ }^{9} 10$ which can also be observed in asymptomatic people. ${ }^{11}$ Scans are typically used to exclude the need for surgery, without offering a clear diagnosis or indicating an alternative treatment. Diagnostic uncertainty can be difficult for patients, ${ }^{12}$ and for some, is interpreted to mean that their symptoms are doubted by the healthcare professionals. ${ }^{13}$ Research has indicated that uncertain aetiology is linked to distress, disability, pain and further treatment 
seeking, ${ }^{14} 15$ which in turn is associated with the reoccurrence of symptoms. ${ }^{16}$

Some patients with PMLBP will be referred on for other conservative interventions, but many (around 42\%) will be discharged without treatment, often because all other alternatives have been exhausted. ${ }^{5}$ Research suggests that these patients receive less reassurance and are less satisfied: instead of accepting the need to self-manage their problem, they feel dismissed, disbelieved and abandoned. ${ }^{17}$ The findings from a prospective cohort study of 296 patients discharged from orthopaedic care without surgery suggest that better communication in consultations with orthopaedic spine clinicians might help reduce distress and unnecessary subsequent healthcare utilisation. ${ }^{5}$ Effective reassurance necessitates engaging with patients and their concerns. For clinicians in orthopaedic teams, this is particularly challenging, as there is only minimal training, if any, in psychologically-informed practice. ${ }^{18}$ Yet, research suggests that these teams see some of the most challenging and complex patients with PMLBP at a point when most other interventions have had little success. Thus, patients who consult and are told that surgery is not indicated are often at the end of the medical-solution journey, and the way in which this message is conveyed to them is pivotal to their willingness to engage with self-management, their subsequent well-being and their healthcare seeking behaviours. The aim of this study was to establish what orthopaedic spine clinicians found difficult in consultations with people with PMLBP for whom surgery was not indicated, and to identify their perceived needs.

\section{METHODS}

\section{Patient and public involvement}

Patients with PMLBP consulting for surgery, who were previously discharged of orthopaedic care, were involved in the design of the study through a focus group. Patients felt that asking surgeons about their perceptions of consultations was the next step following a qualitative study with patients. ${ }^{17}$ It was not appropriate to involve them further in the conduct, reporting or dissemination of this study.

\section{Participant recruitment}

Clinicians eligible to participate were spinal surgeons, and advanced physiotherapy practitioners (APP's), working within a musculoskeletal (MSK) or orthopaedic settings as part of the National Health Service (NHS). The APPs in this study routinely saw people with PMLBP, and were regularly involved in decisions about the suitability of surgery to individual patients. A snowball sampling method was applied, whereby, invitation emails were sent from the clinicians who were part of the research team to their colleagues across the country, and these in turn contacted members of their teams. Those clinicians who were interested to participate contacted the primary researcher to schedule an online interview appointment and provide informed written consent. Participants were not offered reimbursement for taking part in the study. Recruitment took place between April and June 2020.

\section{Semi-structured interview}

Qualitative semi-structured interviews were employed. The interview schedule was developed by the research team, which included two health psychologists (TP and KLB-W), two physiotherapists (LR and AHM) and two orthopaedic spine surgeons (NA and PS). All questions were constructed as open questions with probes as necessary. Clinicians were asked about their age, gender, years of experience, career, additional training, service structure and patient numbers. This was followed by a general exploration of clinicians' practice around explaining persistent back pain when surgery was not indicated. This included questions around the terminology used to describe persistent back pain, how they explain imaging findings to patients, how they deal with patients who are reluctant to accept that surgery will not be offered and how clinicians elicited psychological issues associated with the pain, and incorporated this knowledge into their clinical decisions and their communication with the patients.

All interviews were conducted online via video call, due to COVID-19 restrictions. All interviews were carried out by the same researcher (KLB-W) who was trained in interview skills. Field notes were made after each interview to record the interviewer's impressions of the interview process. Interviews were audio recorded and transcribed verbatim. The data were anonymised, making it impossible to link a comment to a specific participant.

\section{Data analyses}

Data were analysed using QSR International's NVivo software (V.10). The transcriptions were coded and analysed by two researchers (TP and KLB-W), using thematic analysis following the recommendations of Braun and Clarke. ${ }^{19}$ Each transcript was read several times to establish familiarity and contextual impression of the topic. An inductive approach to coding was used, and therefore, no set codes were determined a priori. Descriptive codes were added as they were identified in the data during line-by-line coding of each transcript. Preliminary themes emerged from similar codes that reflected subthemes. The combining of subthemes was used to create higher order themes. Quotations were extracted to illustrate concepts of subthemes. ${ }^{19}$ During this process of the analysis, both positive and negative examples were integrated into (sub)themes. The transcripts were repeatedly reviewed and compared with to ensure (sub) themes correspond to the data. Validity was established through independent coding and comparing by the two researchers (TP and KLB-W), who discussed and refined the themes. Recruitment ended when data saturation was reached, meaning no new subthemes emerged from the interviews. ${ }^{20}$ Given the richness of the data, the (sub) themes and corresponding quotations were condensed 


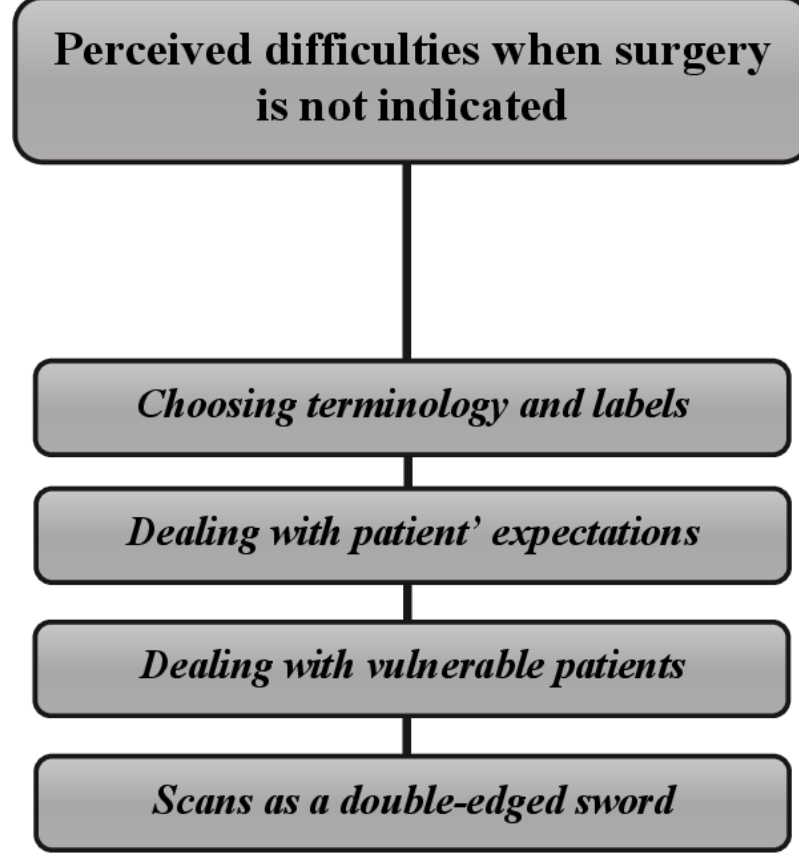

Figure 1 Flow chart of meta-themes and subthemes.

and reviewed by the other coauthors, who are all experts in musculoskeletal low back pain (MLBP) research.

\section{RESULTS}

\section{Description of participants}

In total, 24 interviews accounted for 23 hours and $30 \mathrm{~min}$ of recording. Clinicians are working at 17 different hospitals across the UK and Ireland. Out of the 24 male clinicians, 16 were orthopaedic surgeons, 3 registrars and 5 APPs. On average clinicians were 45.9 years of age and had about 16.8 years of experience with spinal conditions. They reported seeing approximately 15 patients per day from the NHS, and some see patients privately, which was between 5 and 10 patients per week. On average new patients' consultations lasted between 20 and $45 \mathrm{~min}$ and follow-up consultations between 10 and $15 \mathrm{~min}$, although this varied between sites and professional titles. Out of 24 clinicians, 3 APP's stated that they had benefitted from additional psychological training (eg. cognitive behavioural therapy, compassion focused therapy).

\section{Findings}

Findings are grouped into two meta-themes: Perceived difficulties when surgery is not offered, and what clinicians thought might make the consultations better (enablers), for both clinicians and patients. Within these two metathemes, there are several subthemes (see figure 1). Each is presented below with verbatim quotes that highlight the content of the theme. Participants were identified as surgeons (S) or APP's after the participant number.
Clinicians' perceived difficulties when surgery is not indicated Choosing terminology and labels

The majority of clinicians agreed strongly that MLBP, often referred to as 'non-specific' pain, does not require surgery. However, a minority felt that surgery could benefit some of these patients, and that the label 'nonspecific' was ambiguous and open to interpretation. It was also considered a barrier to people being offered surgery, rather than constituting a reliable diagnostic label:

...If I can pick a winner when everyone else has failed, it means that in some way, I'm better than everybody else. It might be that people have been to other people, and said, '“Oh, you've just got this back pain. There's no treatment for you, just go and have physio, or, injections... There isn't going to be a surgical solution..." (W004-S).

Clinicians struggled to find terminology that patients could readily understand and accept. The term 'nonspecific' was commonly used by clinicians, who largely took it to mean that there was nothing specific showing on the scans to explain the pain. There was strong consensus among clinicians that explaining to patients that their pain is not associated with evident pathology on the scan, and therefore surgery would not be offered, was a challenging task. Providing explanations for the pain in these circumstances was especially difficult. Clinicians often used words like 'degenerative' or 'wear and tear' to describe the cause of the pain, and struggled to find analogies that patients could understand: 
...I use things like nonspecific, so that there's no serious or specific cause for your back pain. It's very common in the population. There are lots of issues which input to your pain and your pain is made worse perhaps when you get stressed or when you're not coping very well or through excessive tension... (W003-APP).

...That's really difficult. It gets really complicated to try and explain something, because our vocabulary is so medicalized, that sometimes trying to find the lay words for the things that you're talking about is often really challenging, and the intellect of some patients is very variable. To try and-I don't mean dumb it down in a critical way, but to explain to them in a non-medical way is really difficult... (W018-S).

Some clinicians tried to explain to patients that their pain experience is 'normal', whereas others appreciated the difficulty with trying to normalise patients' back pain, because to patients, it might seem like their experience was disregarded:

...I tell them quite clearly that the back pain is not going to vanish. I tell them quite clearly that lower back pain is a normal lifetime experience... We all suffer it. If $80 \%$ of human beings are going to suffer from lower back pain, it is normal to have back pain... (W011-S).

...I think it's important for them to know that I'm not saying their back is normal. Because it's very easy for them to go away with the feeling that, "Oh God, the doctor just said, there's nothing wrong with my back, whereas it's crippling me." Clearly there is. I'll make that very clear that, whilst I'm explaining that the scan is nothing out of the ordinary, it doesn't mean that I don't appreciate that their back pain is real and very troublesome to them... (W014-S).

Some clinicians chose not to offer explanations for the pain at all:

...I probably wouldn't try honestly. I would say if there is persistent loweback pain, and I don't know what the cause is I'll say "You've got pain that I can't find a cause for." I wouldn't try to find a reason for that... I'm afraid it's a bit brutal in that if you don't have something that I can fix, you don't need me, and, you get discharged... (W007-S).

Other clinicians relied in coaching the message that surgery would not be offered in an overall message of reassurance and good news, thus, instead of focusing on explaining the cause of the pain, they focused on causes that could be eliminated:

...For me, you've got to construct your argument or to create the conversation that it's positive news. I spend a lot of time reassuring them or giving them the good news that this isn't cancer. This isn't an infection or this isn't something that we need to worry about... (W018-S).

\section{Addressing patient' expectations}

Clinicians reported challenges explaining that surgery would not be offered. They identified a group of patients who were particularly difficult to deal with, typically people with a long and complex history of care, who were desperate to find a surgical solution for their pain. In addition, clinicians felt it was difficult to counteract the entrenched information that patients were given throughout their previous care journey:

...this sort of homogenous group of people with primarily pain in their lower back who present to those primary care services, and they push and push and push because they want to see a surgeon or they want to see surgical service, because people see surgery as definitive and they see it as curative... (W024-APP).

...Well, some people are very overt. They will tell you, "I think that's a load of rubbish." Or, "The physio told me that and I didn't believe it then. I still don't believe it now," or whatever. I suppose they might say a statement like "The only way I'm going to get better is if I have surgery." "My GP told me the only way I was going to get better is if I had surgery," or "How can I possibly get better until that disc is removed?" I suppose they'll come up with their own validating statements for their symptoms... (W006-APP).

\section{Consultations with vulnerable patients}

The most difficult group of patients to deliver the message of no surgery to were those who were depressed, angry or anxious. With these patients, the consultation almost invariably ended in tears:

...I always feel more emotionally drained after having seen a patient where there's clearly a lot of emotional distress, and then they find out, they're a little bit tearful in the clinic, or whatever. That obviously has an impact... (W008-S).

For some clinicians, the presence of psychological difficulties was sufficient to exclude surgery. For some, this was accompanied with distrust of the patients' account of their pain experience. Pain, in this context, was defined by the imaging results, rather than the patient, and surgeons backed out of intervening in these cases:

...Yes people that are really angry, and aggressive, and demanding. They want you to chop their head off to make them better. They've got no realistic expectations... (W012-S).

...An abnormal response, is the first thing. If they say to us, "Yes, I've got back pain, but this has stopped me doing this, this, this, and this." I feel subjectively that that's disproportionate. I would then have concerns that their symptoms don't match their signs if you like...If those symptoms and signs don't stack up and 
don't make sense, then that would again indicate that there might be a psychological or functional aspect to the presenting complaint. Finally, if they've got other comorbidities, personality disorders, defined mental health diagnoses, then that would raise the suspicion that the risk benefit ratio might not be in their favour in terms of intervening with them... (W018-S).

... I would grade zero as completely pain free and 10 where you can't even get out of bed. What is your pain? 10. All the time? 10. How have you come to clinic all the way? You've driven two hours to come to this clinic. How can it be 10?... (W013-S).

The majority of clinicians recognised the importance of psychological factors in patients' reported experience of pain, and felt that despite having no training in eliciting issues around mood, beliefs and behaviour, they had acquired sufficient skills through experience to explore these in consultations. However, several clinicians commented that either they struggled to recognise psychological problems, or, that while they could recognise them they felt they lacked skills to respond and manage these:

...The psychology, I think that's where my lack of training is. There are things that I can pick up on, but I don't have any techniques for managing that... (W010-S).

Clinicians not only lack confidence in assessment and differentiation of psychological states, they also expressed concerns about 'tipping someone over the edge', suggesting the discussion of psychological states in clinic may increase patients' hopelessness to an extent that it could even lead to suicide:

...Over the years, we've had several suicides with people with severe back pain and things. You're always very wary about tipping someone over the edge and them losing hope. That's always in the forefront of my mind, is this patient cognisant of their mental health issues and their psychological issues? (W020-APP).

\section{Spinal imaging as a double-edged sword}

For almost all clinicians, use of imaging was the most important factor to help them manage patients' expectations, their vulnerabilities and their understanding and acceptance of why surgery is not offered:

...In patients with persistent pain, it's really difficult to give them enough information and to reassure them without a scan. ... If somebody has persistent unremitting pain, the only way that we can reassure them with confidence, or discharge them, is with a scan....Sometimes we would do a scan to reassure the patient, even though we don't think it's going to show anything. Yes. It gives the patient the confidence that there's nothing significantly wrong... (W018-S).
Although several clinicians mentioned that it was much easier to reassure patients with a scan, their narrative suggested that the scans served to reassure themselves at least as much as their patients:

...I think it's much easier to reassure with a scan. If I'm reassuring something without a scan, I'm doing so with my fingers crossed, below my back, that they're not harbouring some problem that I haven't picked up on. People will talk to you about back problems and you can examine them. Actually, until you've seen some imaging, you cannot really pull it all together, so imaging is key. As a rule of thumb, I dislike making judgments and discharging people who have a lot of symptoms unless I've seen some imaging... (W001-S).

However, for a minority of clinicians, the presence of a negative scan actually made things harder, especially with patients who were severely disabled by their pain:

...I will scan people who seem to come with dreadful back pain and the scans are completely normal. Once again, even more problematic in a way because I can tell you what's not wrong. I just haven't got a clue what is wrong. They stare at you. "You're the doctor. You tell me." You're like, "I don't know... (W015-S).

A small number of clinicians felt that focusing on the scan created more fear and confusion, and should be avoided if possible:

...Well, I try and move the focus of the consultation away from the scan as quickly as I can, personally. If I can get away with it—of just letting them know that I've seen your scan and there's nothing on there that my surgical colleagues will be interested in, then I'll try that. Then I'll feel my way. If I get the sense that that isn't going to be enough, I might quickly show them the result on the screen. My starting point is not to show them... (W006-APP).

\section{What would help to make the consultation better}

There were a set of factors that clinicians felt would make things easier for both patients and practitioners:

\section{Managing expectations}

Clinicians felt that it is important to convey to patients at an early stage of their care episode that surgery will most likely not be offered for their PMLBP, so that they will not expect surgery when consulting orthopaedic spinal teams later on. Addressing patients' prior expectations emerged as an important theme. Clinicians recognised the disappointment this may cause to patients who assumed they would be offered a cure. One clinician compared this to taking a child to the ice cream shop but then refusing to buy them ice cream:

...You told him you're taking him to the ice cream shop, right?... So when I have told somebody or somebody has been given a clear cut thing that 
surgery is the answer for your problem, that's where the difficulty is... They were told categorically that I will operate. I'll make you better. Patients cling on to that... (W013-S).

\section{Use of routine imaging}

The majority of patients coming into an orthopaedic setting will have had a pre-appointment imaging test, and clinicians felt that this saved time and effort. Some also felt that if scans were perceived as a routine procedure, patients might reduce their expectations that scans will provide a clear diagnosis, and an obvious solution to their pain. In addition, some reported routine scans reduced appointments and waiting time for patients.

... I think my ideal is to get people scanned before they see me for the first time, so that I've got some conclusion that can be drawn at that first meeting... If I see somebody at the first meeting, and I then send them away for the MRI scan, it may be another two months before they've had the damn thing... I think the hospitals will see the sense in that because, otherwise, I see them without a scan, I can't reach any conclusion, and then they have another appointment in the hospital once they've had the scan. It doubles the outpatient attendance... (W001-S).

\section{Triage}

Clinicians also felt that better preparation by general practitioners (GPs), or other healthcare providers who might perform a triage to exclude those not suitable for surgery would be useful. Most of the clinicians said they prefer as much prior triaging as possible, and some expressed frustration with primary care referrals that failed to apply triage. Despite some reservations about the quality of triage, the overall opinion was that there is a strong need for creating a consistent pathway in which triage occurs by a skilled MSK team, rather than direct entry from a referral by GPs:

...I'm not sure they've been filtered out by the GP. GPs just generally take the path of least resistance. If the patient isn't really getting any better, then they just refer them on, and it seems speculative... (W023-S).

...If you're never going to operate on someone, you don't want them taking up the time from purely an economic point of view in terms of opportunity cost... (W015-S).

However, triage was not always perceived as an enabler. Some clinicians felt that no matter how thorough the prior triaging is, patients who are fixated on surgical solutions will always manage to get through to them. Some clinicians also outlined the dangers inherent in triage being done by non-surgeons, and in the absence of imaging:

...but again, you need to say, on what basis are they doing the triage? Are they looking at scans? Are they just reading a letter from the GP? Triaging has to be done quite carefully I think... The problem with that is, really, only a surgeon can say whether somebody is going to be likely to benefit from surgery... Ideally, everybody would be run past the surgeon...(W001-S).

\section{Access to direct referral elsewhere}

One of the options that could help improve consultations in which surgery is ruled out is direct referral to other treatments, such as pain management, but within the NHS in the UK, this was not always available:

...If they want access to a generalized pain clinic, then they go back to their GP, and the GP refers them to the pain clinic. Equally, if it's felt that they need other assessment or treatment, then they'll go back through the GP... (W008-S).

... pain management programs, despite being sort of highly championed by ... every single report that's been commissioned in the last decade, the commissioning framework has manifestly failed to adopt that, and these things are rarely available in most areas in the UK. It's just nonsense really... (W024-APP).

\section{'Passing the buck' to other professionals}

Several clinicians felt that other professionals, especially APPs, would do a much better job at addressing the needs of patients when surgery is not recommended. They considered that it was a combination of inherent characteristics, training and experience, which resulted in surgeons being less suitable to handle psychosocial aspects in patients. While some of them commented that having psychologists as part of the team would be useful, they also recognised that the resource implications would probably make this impossible. In addition, several thought that there would still be a need for surgeons to make an appearance-that the surgeons' authority was needed to legitimise the decision:

...I'm a surgeon, so I think more mechanically; this is a mechanical problem and this is how we can address it. Whereas my APP's... they're not surgeons, they don't like to use a knife, they're nice people... That's a fact. They have that nice, touchy, comforting feeling. When the person goes into the room, there's a nice person who listens to them... I often say if somebody requires non-operative management, they are probably better off treating them than I am... (W011-S).

...Some patients want to see a qualified surgeon and until they see that person they're not going to accept what anyone says, no matter how qualified or how experienced the person is... but then I can come in and give-if you like-the surgeon's validation to their pain and suffering... (W005-S).

\section{Training}

Clinicians agreed in general that there was a need for better training in communication skills and education 
around psychosocial aspects of living with pain. Some thought the most effective time for training was in early years of medical education, but others felt that only experience could hone such skills. Others thought these types of skills were part of a person's characteristics and could not be learnt. Some considered that training might teach surgeons to imitate empathy when they were not feeling it, and there was a suggestion from a small group that at present, empathy was not considered important in the surgeons' scope of practice, though that might change:

...It can be trained but I think it's inherent and I'm not sure if it can be-It's definitely linked to how exhausted you are at the time and the amount of stresses that you have around own life at the time. I think it certainly can be trained. It can be pretended, it can be put on. (W005-S).

.... I think if it was demonstrated really clearly that it was a benefit for them to be more empathetic, probably people would be persuadable to change... (W001-S).

Several clinicians mentioned that the single most effective component requiring training to improve consultations was learning to be an effective listener. Some also considered that training in psychosocial approaches would save time in consultations:

...The single biggest change in my practice of anything that I've ever done was to start doing reflective listening. That was the single biggest thing that, of all the things I've learned, that's been the most helpful with patients. It's really easy. It is really effective... (W006-APP).

...If we're better trained in CBT [Cognitive Behavioural Therapy] and in deliverance of looking at psychology and back pain, I think that we could probably find models of being able to get over the salient points and unravel things in a quicker way. That would be exciting work, wouldn't it?...' (W003-APP).

Clinicians expressed a variety of ideas on how training might be best offered to orthopaedic teams, with support for feedback from experts on videotaped consultations.

...I'd love to have some videos of my consultations, and for somebody with that kind of training who is good at that to look at those videos and just give me some constructive feedback on it...I think that it might be quite nice to-As part of our appraisal process to have a way of somebody looking at videos of our consultations every now and then and giving some feedback... (W010-S).

\section{DISCUSSION}

Clinicians in this study found consultations where surgery is not indicated challenging, especially when dealing with distressed and/or cure-seeking patients who are reluctant to accept that surgery is not an option. They reported concerns about working with vulnerable patients and eliciting psychological issues, and recognised that there was a need for enhanced communication skills with these patients, and for clear educational messages tailored to individuals. They also suggested that better preparation of patients for the consultation could help align patients' expectations.

Many of the difficulties reported by clinicians in this study have been recognised in previous research: These include patients' unrealistic expectations that the specialist will offer surgery or a 'cure'. According to Lewis and O'Sullivan ${ }^{21}$ such expectations are likely to originate from previous health professionals. The authors emphasise the need to reframe the way PMLBP is dealt with through honest, open and sensitive communication regarding the evidence, emphasising that there is no magic cure for this persistent and disabling condition but instead directing patients towards informed self-management.

Clinicians also described the challenge of assessing and responding to psychological issues presented by patients, especially when faced with vulnerable, angry or upset patients. The results of a survey study of 350 US-based orthopaedic surgeons found that while they are likely to notice and discuss psychological issues, they felt they lack the ability to formally screen or refer for psychological treatment. The reported barriers to screening, noticing and discussing psychosocial factors, and to referring to psychological treatments, were lack of time, the stigma associated with psychological labels and feeling uncomfortable. However, survey responders did not endorse beliefs that a biomedical model alone is sufficient to treatment, which indicates that they do recognise the role of psychological factors. ${ }^{22}$ Our findings are important, because there is growing evidence for the role of effective reassurance ${ }^{23}$ with clear pain and suffering validation statements to legitimise symptoms. ${ }^{1724-28}$

Clinicians described finding the best terminology to discuss PMLBP with patients as challenging, when no clear physical cause could be described. The evidence suggests this is an important aspect of the consultation: Patients require clear, concise, personalised and consistent information regarding their diagnosis, prognosis, management options including self-management strategies, prevention and directions to support services. ${ }^{23}$ Furthermore, patients require this information to be conveyed in a suitable tone and understandable language. ${ }^{17} 23$ Participants did not comment or refer to patients' health literacy directly, even when discussing their difficulties in choosing appropriate terminology. Previous research has suggested that orthopaedic clinicians typically are highly skilled in technical knowledge, but low in communication skills. ${ }^{29}{ }^{30}$ They often use jargon that patients struggle to understand, ${ }^{31} 32$ and sometimes resort to oversimplification that patients find belittling and at odds with their experience (eg, wear and tear). ${ }^{17}$ Although there is mounting evidence that psychological factors are 
more effective predictors of MLBP than pathoanatomical factors ${ }^{33}$ clinicians still emphasise biomedical issues, with a focus on pathoanatomical language. ${ }^{34}$

Despite guidelines suggesting that imaging is not recommended for people with PMLBP, ${ }^{835}$ clinicians felt that MRI scans are a necessity and their primary diagnostic tool that reassures them that they have not missed any serious underlying pathology. ${ }^{6}$ Clinicians also felt MRI scans were expected and desired by most patients, who hoped these would indicate a clear diagnosis. In practice, only a minority of patients consulting orthopaedic spine clinics in the UK enter their specialist consultation without imaging results. ${ }^{5}$ For this group, reduction in imaging might be carried out through effective triage, to ensure that the majority of people turning up for surgical consultations were indeed surgical candidates. The overall message from clinicians was that people with PMLBP were not a good 'fit' to what they had to offer, and at least in part, a solution would be to ensure that they saw someone else.

Clinicians expressed the opinion that providing patients, who have often tried all treatments to no avail and experience entrenched pain and disability, with a meaningful management plan is challenging. One of the main problems identified was the lack of accessibility to direct pain management services, in a system that typically has the GP as a gatekeeper to services, and in which pain management programmes remain oversubscribed. Another reported barrier to referral to pain management was patients' expectations and beliefs, which were often strongly biomechanical. Clinicians were reluctant to challenge these beliefs, and felt they did not have the time or skill to address the issue. The dilemma expressed by our clinicians has been recognised in the literature, which states that it is essential for clinicians to consider patients preferences when formulating a treatment plan, ${ }^{36}$ that consultations should entail assessment of patient's openness towards a biopsychosocial explanation or acceptance of patients' reliance on the biomedical model of illness ${ }^{37}$ and lastly, recommends working with one explanatory model that fits patients experience and personal narratives. ${ }^{38-40}$ However, in contrast, there is also some evidence suggesting that challenging patients' biomedical beliefs may be beneficial. Qualitative research with people living with PMLBP consulting GPs has suggested a paradox for patients, in that, by recognising that they cannot arrive at a definitive diagnosis and cure, they start questioning their knowledge and beliefs and ultimately recognise the biomedical model may not fit their experience. ${ }^{39}$ This tension may allow an opportunity for positive change by helping patients to move towards the biopsychosocial model. Consultations with orthopaedic teams might provide a similar opportunity for change, amplified by the fact that imaging results and a specialist opinion fail to deliver biomechanical certainties about PMLBP.

This study has several limitations. The interviews and primary analysis were conducted by the same researcher (KLB-W); however, the risk of bias was identified and steps were taken to minimise its influence. Clinicians were aware of the interviewer's professional background (psychology), which may have influenced their responses. The study focused on UK-based clinicians, and is unlikely to represent other health settings. There is a lack of female participants in this study, which may lead to knowledge gaps of female orthopaedic spine clinicians. Although this represent the gender distribution in the profession in the UK, it may lead to a bias perspective, and may result in representing a male provider bias. This may also obscure information on communication patterns between provider gender and patient gender. It is highly possible that the clinicians who chose to talk to us were not representative of larger groups, as they are more likely to have an interest in the topic.

In conclusion, this study leads to a better understanding of UK-based orthopaedic clinicians' perceptions of barriers to optimal care delivery and possible improvements in care for a common group of patients for whom surgery is not indicated. Findings suggest that there may be a need and appetite for upskilling clinicians to deliver effective reassurance in simple and understandable language to ensure that patients receive comprehensible and consistent information. In addition, the study indicates there may be suboptimal processes along the care pathway, which create unrealistic expectations in patients.

\section{Author affiliations}

${ }^{1}$ Psychology, Royal Holloway University of London, Egham, UK

${ }^{2}$ Orthopaedic, Wexham Park Hospital, Slough, UK

${ }^{3}$ Department of Surgery and Cancer, Imperial College London, London, UK

${ }^{4}$ Health Sciences, University of Southampton, Southampton, UK

${ }^{5}$ Department of Orthopaedics, Leicester University Hospitals, Leicester, UK

${ }^{6}$ Department of Psychology, University of London, London, UK

\section{Twitter Lisa Roberts @LPhysioprof}

Acknowledgements The authors thank all orthopaedic clinicians who participated in this study. We thank the people from our Patient and Public Involvement panel for their contribution to this study.

Contributors $\mathrm{KLB}-\mathrm{W}$ conducted the interviews. TP and KLB-W were involved in data analysis. All authors (KLB-W, NA, LR, AHM, PS and TP) were involved in the study design, interpretation and write-up.

Funding This work was supported by the charity EUROSPINE, grant number (TFR2019-2). The content of this study is the sole responsibility of the authors; the financial sponsor had no role in the study design, data collection, data analysis, data interpretation, preparing the manuscript or the decision to submit for publication.

Competing interests TP has held consultancy roles teaching Psychologically Informed Practice through her University position. The other authors declare no conflict of interest.

Patient and public involvement Patients and/or the public were involved in the design, or conduct, or reporting, or dissemination plans of this research. Refer to the Methods section for further details.

Patient consent for publication Consent obtained directly from patient(s)

Ethics approval This study was granted ethical approval from NHS Bloomsbury Research Ethics Committee (20/L0/0290) and the Ethics Committee at Royal Holloway, University of London.

Provenance and peer review Not commissioned; externally peer reviewed.

Data availability statement Data are available upon reasonable request. All data relevant to the study are included in the article or uploaded as supplementary information. Individual participant data that underlie the results reported in this 
article, after de-identification, are shared. All data relevant to the study are included in the manuscript. The study protocol, informed consent form and the coding framework in NVivo can be made available upon reasonable request.

Open access This is an open access article distributed in accordance with the Creative Commons Attribution Non Commercial (CC BY-NC 4.0) license, which permits others to distribute, remix, adapt, build upon this work non-commercially, and license their derivative works on different terms, provided the original work is properly cited, appropriate credit is given, any changes made indicated, and the use is non-commercial. See: http://creativecommons.org/licenses/by-nc/4.0/.

\section{ORCID iDs}

Kathrin Louise Braeuninger-Weimer http://orcid.org/0000-0002-9880-8686 Lisa Roberts http://orcid.org/0000-0003-2662-6696

\section{REFERENCES}

1 Foster NE, Anema JR, Cherkin D, et al. Prevention and treatment of low back pain: evidence, challenges, and promising directions. The Lancet 2018;391:2368-83. doi:10.1016/S0140-6736(18)30489-6

2 Fritzell $P$, Hägg $O$, Nordwall A. Complications in lumbar fusion surgery for chronic low back pain: comparison of three surgical techniques used in a prospective randomized study. A report from the Swedish lumbar spine Study Group. Eur Spine J 2003;12:178-89. doi:10.1007/s00586-002-0493-8

3 Willems PC, Staal JB, Walenkamp GHIM, et al. Spinal fusion for chronic low back pain: systematic review on the accuracy of tests for patient selection. Spine J 2013;13:99-109. doi:10.1016/j. spinee.2012.10.001

4 Greenough C. The National back pain pathway. NHS, 2016. Available: https://www.england.nhs.uk/blog/charles-greenough/

5 Braeuninger-Weimer K, Rooslien H, Anjarwalla N. 'Reassurance and healthcare seeking in people with persistent musculoskeletal low back pain consulting orthopaedic spine practitioners: A prospective cohort study'. Eur. J. Pain 2021;25. doi:10.1002/ejp.1765

6 Chou R, Fu R, Carrino JA, et al. Imaging strategies for low-back pain: systematic review and meta-analysis. Lancet 2009;373:463-72. doi:10.1016/S0140-6736(09)60172-0

7 Koes BW, van Tulder M, Lin C-WC, et al. An updated overview of clinical guidelines for the management of non-specific low back pain in primary care. Eur Spine J 2010;19:2075-94. doi:10.1007/s00586010-1502-y

8 O'Connell NE, Cook CE, Wand BM, et al. Clinical guidelines for low back pain: a critical review of consensus and inconsistencies across three major guidelines. Best Pract Res Clin Rheumatol 2016;30:968-80. doi:10.1016/j.berh.2017.05.001

9 Chou D, Samartzis D, Bellabarba C, et al. Degenerative magnetic resonance imaging changes in patients with chronic low back pain: a systematic review. Spine 2011;36:S43-53. doi:10.1097/ BRS.0b013e31822ef700

10 Weishaupt D, Zanetti M, Hodler J, et al. Painful lumbar disk derangement: relevance of endplate abnormalities at MR imaging. Radiology 2001;218:420-7. doi:10.1148/radiology.218.2.r01fe15420

11 Brinjikji W, Luetmer PH, Comstock B, et al. Systematic literature review of imaging features of spinal degeneration in asymptomatic populations. AJNR Am J Neuroradiol 2015;36:811-6. doi:10.3174/ ajnr.A4173

12 Serbic D, Pincus T. Chasing the ghosts: the impact of diagnostic labelling on self-management and pain-related guilt in chronic low back pain patients. J Pain Manag 2013;6:25-35.

13 Mounce K. Back pain. Rheumatology 2002;41:1-5. doi:10.1093/ rheumatology/41.1.1

14 Serbic D, Pincus T, Fife-Schaw C, et al. Diagnostic uncertainty, guilt, mood, and disability in back pain. Health Psychol 2016;35:50-9. doi:10.1037/hea0000272

15 Serbic D, Pincus T, Holloway R. Diagnostic uncertainty and recall bias in chronic low back pain. Pain 2014;155:1540-6.

16 Carlson $\mathrm{H}$, Carlson N. An overview of the management of persistent musculoskeletal pain. Ther Adv Musculoskelet Dis 2011;3:91-9. doi:1 $0.1177 / 1759720 \times 11398742$

17 Braeuninger-Weimer K, Anjarwalla N, Pincus T. Discharged and dismissed: a qualitative study with back pain patients discharged without treatment from orthopaedic consultations. Eur J Pain 2019;23:1464-74.
18 Tongue JR, Epps HR, Forese L. Communication skills for patientcentered care. Research-Based, easily learned techniques for medical interviews that benefit orthopaedic surgeons and their patients. J Bone Jt Surgery 2005;87:652-8.

19 Braun V, Clarke V. Using thematic analysis in psychology. Qual Res Psychol 2006;3:77-101. doi:10.1191/1478088706qp063oa

20 Saunders B, Sim J, Kingstone T, et al. Saturation in qualitative research: exploring its conceptualization and operationalization. Qual Quant 2018;52:1893-907. doi:10.1007/s11135-017-0574-8

21 Lewis J, O'Sullivan P. Is it time to reframe how we care for people with non-traumatic musculoskeletal pain? Br J Sports Med 2018;52:1543-4. doi:10.1136/bjsports-2018-099198

22 Vranceanu AM, Beks RB, Guitton TG, et al. How do orthopaedic surgeons address psychological aspects of illness? Arch Bone Jt Surg 2017;5:2-9.

23 Lim YZ, Chou L, Au RT, et al. People with low back pain want clear, consistent and personalised information on prognosis, treatment options and self-management strategies: a systematic review. $J$ Physiother 2019;65:124-35. doi:10.1016/j.jphys.2019.05.010

24 Edmond SN, Keefe FJ. Validating pain communication: current state of the science. Pain 2015;156:215-219-9. doi:10.1097/01.j.pain. $0000460301.18207 . c 2$

25 Linton SJ, Boersma K, Vangronsveld K, et al. Painfully reassuring? the effects of validation on emotions and adherence in a pain test. Eur J Pain 2012;16:592-9. doi:10.1016/j.ejpain.2011.07.011

26 Vangronsveld KL, Linton SJ. The effect of validating and invalidating communication on satisfaction, pain and affect in nurses suffering from low back pain during a semi-structured interview. Eur J Pain 2012;16:239-46. doi:10.1016/j.ejpain.2011.07.009

27 Edlund SM, Carlsson ML, Linton SJ, et al. I see you're in pain - The effects of partner validation on emotions in people with chronic pain Scand J Pain 2015;6:16-21. doi:10.1016/j.sjpain.2014.07.003

28 Edlund SM, Wurm M, Holländare F, et al. Pain patients' experiences of validation and invalidation from physicians before and after multimodal pain rehabilitation: associations with pain, negative affectivity, and treatment outcome. Scand J Pain 2017;17:77-86. doi:10.1016/j.sjpain.2017.07.007

29 Frymoyer JW, Frymoyer NP. Physician-Patient communication: a lost art? J Am Acad Orthop Surg 2002;10:95-105. doi:10.5435/00124635-200203000-00005

30 Kyle S, Shaw D. Doctor-patient communication, patient knowledge and health literacy: how difficult can it all be? Ann $R$ Coll Surg Engl 2014;96:e9-13. doi:10.1308/rcsbull.2014.96.6.e9

31 Laerum E, Indahl A, Skouen JS. What is "the good backconsultation"? A combined qualitative and quantitative study of chronic low back pain patients' interaction with and perceptions of consultations with specialists. J Rehabil Med 2006;38:255-62.

32 Kampa RJ, Pang J, Gleeson R. Broken bones and fractures - an audit of patients' perceptions. Ann R Coll Surg Engl 2006;88:663-6. doi:10.1308/003588406X149192

33 Hartvigsen J, Hancock MJ, Kongsted A, et al. What low back pain is and why we need to pay attention. Lancet 2018;391:2356-67. doi:10.1016/S0140-6736(18)30480-X

34 Stewart M, Loftus S, Sticks LS. Sticks and stones: the impact of language in musculoskeletal rehabilitation. J Orthop Sports Phys Ther 2018;48:519-22. doi:10.2519/jospt.2018.0610

35 Maher C, Underwood M, Buchbinder R. Non-Specific low back pain. Lancet 2017;389:736-47. doi:10.1016/S0140-6736(16)30970-9

36 Dima A, Lewith GT, Little P, et al. Identifying patients' beliefs about treatments for chronic low back pain in primary care: a focus group study. Br J Gen Pract 2013;63:e490-8. doi:10.3399/bjgp13X669211

37 Allegretti A, Borkan J, Reis S, et al. Paired interviews of shared experiences around chronic low back pain: classic mismatch between patients and their doctors. Fam Pract 2010;27:676-83. doi:10.1093/fampra/cmq063

38 Toye F, Barker K. Persistent non-specific low back pain and patients experience of general practice: a qualitative study. Prim Health Care Res Dev 2012;13:72-84. doi:10.1017/S1463423611000387

39 Toye F, Barker K. 'Could I be imagining this?' - the dialectic struggles of people with persistent unexplained back pain. Disabil Rehabil 2010;32:1722-32.

40 Toye F, Barker K. 'I can't see any reason for stopping doing anything, but I might have to do it differently'--restoring hope to patients with persistent non-specific low back pain--a qualitative study. Disabil Rehabil 2012;34:894-903. doi:10.3109/09638288.201 1.626483 